\title{
The Influence of Energy Output And Substitution On The Environmental Impact of Waste-To-Energy Operation. Quantification By Means of A Case Study.
}

Elizabeth Zoe Boakes ( $\sim$ boakeslizzie@gmail.com )

KU Leuven: Katholieke Universiteit Leuven https://orcid.org/0000-0001-6204-4971

Jan-Kees De Voogd

Indaver

Guido Wauters

Indaver

Jo Van Caneghem

KU Leuven: Katholieke Universiteit Leuven

Research Article

Keywords: Waste-to-Energy, Life Cycle Assessment, Circular economy, Sustainable waste management, Material recovery from waste

Posted Date: July 27th, 2021

DOI: https://doi.org/10.21203/rs.3.rs-714667/v1

License: (c) (i) This work is licensed under a Creative Commons Attribution 4.0 International License. Read Full License

Version of Record: A version of this preprint was published at Clean Technologies and Environmental Policy on April 2nd, 2022. See the published version at https://doi.org/10.1007/s10098-022-02297-y. 


\section{Abstract}

A Life Cycle Assessment (LCA) was conducted to evaluate the total environmental impact of state-of-theart Waste-to-Energy (WtE) in Belgium, with respect to recovered energy utilization and addition of Carbon Capture and Storage (CCS). Four energy output scenarios were modelled on Umberto LCA software using primary data of mass and energy flows surrounding the six incinerators at the considered WtE plant, and predefined processes from the Ecoinvent 3.6 database. The normalized LCA results suggest that by utilizing all the recovered energy as steam, the WtE plant can avoid an equivalent annual environmental impact value of approximately 21200, 36800, 6700, 15800, 37000 and 6900 average European citizens in the impact categories 'climate change', 'freshwater and terrestrial acidification', 'freshwater eutrophication, 'photochemical ozone creation' and 'respiratory effects, inorganics', 'terrestrial eutrophication', respectively. The 'Electricity and Steam with CCS' scenario resulted in the most avoided environmental impact in the impact category 'climate change'. However, in all other impact categories, it resulted in less avoided environmental impact compared to the 'Steam' scenario. The comparative analysis showed that 19 out of 24 of the LCA results varied by more than $50 \%$ between two energy substitution models, thus quantifying the influence of energy substitution in LCA modelling. This study exemplifies the environmental benefit WtE technology can realize by substituting conventional energy production processes that are reliant on fossil resources, whilst performing its primary function that is reducing the volume of non-recyclable waste, destroying hazardous organic components it contains and recovering useful materials from it.

\section{Introduction}

Energy recovery from municipal solid waste (MSW) through incineration, i.e. Waste-to-Energy (WtE), plays a crucial role within current and future waste management schemes due to the sustainability benefits it provides. The ability it creates to recover both energy contained in non-recyclable waste, as well as valuable materials from bottom ash, proves its role as an essential and compatible technology within sustainable waste management (Van Caneghem et al., 2019; Quicker et al., 2020). WtE diverts nonrecyclable waste from landfill and substitutes finite primary resources in conventional production processes with secondary resources, proving that WtE is a key factor in sustainability transitions (De Greef et al., 2018). In addition, the high fraction of biogenic carbon in MSW ensures that WtE contributes to energy transitions by avoiding the use of fossil-based fuels.

In view of the recently announced Circular Economy Action Plan (CEAP), EU member states are encouraged to adopt, or update, their national circular economy strategies, plans and measures in light of CEAP's ambitions, e.g., creating a well-functioning EU market for secondary raw materials, and, enhancing circularity in a toxic-free environment (European Commission, 2020). The circular economy should generate new and sustainable competitive advantages for Europe by protecting businesses against scarcity of resources and volatile prices (European Commission, 2015). The essential role that WtE holds within the circular economy is threefold. Firstly, it recovers secondary resources thereby closing material loops and recovers secondary raw materials which otherwise wouldn't be recoverable using traditional 
mechanical and chemical techniques (Grosso, 2016; Margallo et al., 2018). Secondly, it safeguards the quality of recycled material streams by removing and thermally treating low-quality waste streams (Schneider \& Ragossnig, 2015). Finally, it destroys hazardous organic components, e.g., persistent organic pollutants (POPs), which are present at low concentrations in domestic and industrial nonhazardous waste. Therefore it prevents unwanted dispersion of toxic substances, and contributes to the realization of a toxic-free environment (Brunner \& Rechberger, 2015; Kral et al., 2019), which is one of goals of the EU Green Deal (European Commission, 2019). Furthermore, WtE technology can be strategically positioned in sustainable industrial symbiosis (IS), wherein the recovered energy from the WtE plant, e.g., high-pressure steam, is delivered to neighboring industry via local networks, thus providing local companies a competitive advantage, as well as a stable supply of energy.

LCA is a tool frequently used to quantify the environmental impacts of WtE systems. The results of existing LCA studies provide a variety of insights on WtE systems and the effects of system variables on the life-cycle burdens. Some of the system variables investigated include, input waste composition (Demetrious et al., 2018; Zhou et el., 2018), avoided conventional production of heat or electricity (Burnley et al., 2015; Jeswani \& Azapagic, 2016), and the recovery of the metal or aggregate from the bottom ash (Boesch et al., 2014; Burnley et al., 2015). However, LCA studies involving WtE in literature often compare the global warming potential of scenarios that utilize different WtE technologies (e.g., landfill, gasification, incineration), the addition of Carbon Capture and Storage (CCS) to WtE technology remains under researched. In a recent review of $101 \mathrm{LCA}$ studies of different WtE valorization technologies, only 25 studies included results for impact categories (ICs) other than global warming, of which, 22 were comparative LCA studies, where scenarios representing different WtE technologies were compared using a common unitary functional unit, being the treatment of MSW (Dastjerdi et al., 2021). The research conducted by Lausselet et al. (2017) was the only study in Dastjerdi et al. (2021) review that investigated the addition of CCS to WtE technology, wherein WtE coupled with CCS was compared to standard WtE operation, landfill and recycling scenarios. A general conclusion from existing comparative WtE LCA studies, is that uncertainty is introduced whilst modelling energy systems, specifically whilst assuming substituted energy production processes and energy efficiencies, which have a significant influence on the overall LCA results of MSW treatment schemes (Astrup et al., 2015; Dastjerdi et al., 2021).

In contrast to existing literature, the aim of this study is to quantify and discuss, by means of a case study, the influence of various energy output scenarios, e.g., electricity or steam production, and energy substitution on the environmental impact values of six ICs for real scale, existing WtE plant operating in a combined heat and power scheme. In order to thoroughly quantify the WtE operation, all six resultant environmental impacts were broken down according to individual causative processes or pollutants, which has yet been done in previous literature.

This study considers a state-of-the-art WtE plant which is strategically positioned in IS with neighboring chemical industry; Indaver/Sleco's WtE plant in Doel, Belgium, is connected to both a steam turbine and the surrounding chemical industry via a high-pressure steam network (ECLUSE). To investigate how Indaver/Sleco can utilize the recovered energy from their WtE plant in Doel to best mitigate environmental 
impact, an attributional LCA was conducted to critically evaluate the total environmental impact of the WtE plant with respect to recovered energy utilization and addition of CCS. A comparative analysis between two LCA models analyzed how the assumed avoided conventional energy production processes influence the overall environmental impact of the WtE plant for six EF 2.0 ICs. The results of the comparative analysis will therefore quantify the extent to which energy substitution influences the overall results of the LCA model.

\section{Methodology}

\subsection{Functional unit}

Given the research question - How can Indaver/Sleco utilize the recovered energy from WtE to best mitigate their annual environmental impact? - the functional unit was defined as the utilization of 8957 TJ of energy (which was the total recovered energy, primarily recovered in the form of high-pressure steam, see Table 1) in Indaver/Sleco's WtE plant in Doel during 2018.

\subsection{Scope \& system boundaries}

The scope of the LCA is restricted to the thermal treatment of non-recyclable MSW at Indaver/Sleco's site in Doel during 2018.

The system boundaries comprise all incineration processes that occur on Indaver/Sleco's WtE site in Doel, namely the three grate and three fluidized bed incinerators. The hot flue gas, produced during the incineration of MSW, is led through a steam boiler where the energy is recovered in the form of highpressure steam $\left(40\right.$ bars, $\left.400^{\circ} \mathrm{C}\right)$. The steam then flows either to a steam turbine to produce electricity ( $20 \%$ electrical efficiency) or is delivered directly to the ECLUSE steam network (assumed to have $100 \%$ energy efficiency). The downstream processes related to the bottom ash and air pollution control (APC) residues (i.e., dedicated hazardous waste landfilling onsite) were included within the system boundaries. Scrap metal treatment processes for recovered steel, aluminum and copper, that are extracted from the waste streams and bottom ash, were also included within the system boundaries to compensate for the reduced quality in comparison to primary metals, thus allowing equivalent mass substitution assumptions. Additionally, in one of the considered scenarios, a CCS process was assumed to be on site and thus considered within the system boundaries. The collection and transportation of the MSW to the WtE plant are not included within the system boundaries of the LCA models as previous studies have shown that impacts of waste transport rarely has a large influence on overall system environmental impacts (Laurent et al., 2014; Thyberg \& Tonjes, 2017). The WtE plant infrastructure was not modelled in the LCA models as preliminary results showed that the relative environmental impacts associated with the infrastructure are negligible. Figure 1 illustrates the system boundaries described.

In Fig. 1 all rectangular processes located within the green area result in an environmental impact that has a positive value. Whereas, all rectangular processes within the red area are avoided processes and, therefore, their resulting environmental impacts have a negative value. The processes located outside of 
either the green or red area are not considered within the system boundaries of this study. The solid arrows represent mass or energy flow between two processes. The dashed arrows, between the green and the red area, represent an equivalent substitution relation between mass or energy supplied by the WtE plant, and, the corresponding avoided conventional production process.

\subsection{LCA methodology}

The LCAs were conducted using Umberto software, using the Environmental Footprint (EF) 2.0 impact assessment method. The ICs used in this study were chosen based on their recommendation level ( $R L)$, limited to RL1 and RL2, and their relevance to the study. The environmental impacts were normalized to an average European citizen equivalent (AECE) value using the corresponding normalization factor provided by the European Commission for the EF 2.0 LCA package (European Commission, 2018).

\subsection{LCA model description and inventory}

Indaver/Sleco's WtE plant in Doel comprises three grate incinerators and three fluidized bed incinerators, all incinerators operate simultaneously in two lines: the grate incinerator line and the fluidized bed incinerator line. The functionality of both grate and fluidized bed incinerators have been described in detail in previous work (Vandecasteele et al., 2007; Van Caneghem et al., 2010), however to support the understanding of the incinerator inventory used in this study, here is a brief description of the WtE plant: the grate incinerators combust roughly 430000 tons of MSW and similar industrial waste on three moving grates annually. The bottom ash remaining at the end of the grate is collected via a wet ash extractor. The quenched bottom ash is further treated on site, consisting of washing, screening and ferrous and nonferrous metal extraction. The flue gas cleaning consists of lime and activated carbon injection in a spray dryer, removal of the formed flue gas cleaning residues in a bag filter followed by wet scrubbing and injection of a limestone slurry and subsequent removal of the formed gypsum residue. The three fluidized bed combustors treat roughly 650000 tons of non-hazardous industrial waste and wastewater treatment sludge annually. After the industrial waste has been shredded and the ferrous metals extracted, the industrial waste is then combined with the sludge and fed on top of a fluidized sand bed. Non-ferrous metals are extracted from the bottom ash obtained from the sand bed. The flue gas cleaning consists of dedusting in an electrostatic precipitator after the boiler, followed by injection of lime and lignite in a Circoclean reactor. After removal of the formed flue gas cleaning residue in a bag filter, the flue gases flow through a final alkaline scrubber before being emitted at the stack. In both incinerator lines, fly ash is also collected at the flue gas side of the steam boilers.

Indaver/Sleco provided primary operational data collected onsite: the 2018 annual combined mass and energy flows for each incinerator line, see Table 1. The data in the column 'Grate Incinerator line' and 'Fluidized Bed Incinerator line' in Table 1 were used to create self-defined processes in the LCA model which incorporate the incineration of MSW and flue gas cleaning for each incinerator line. The maximum value was assumed in the self-defined processes with regards to Mercury, Cadmium and Thallium. The entire WtE plant was modelled by combining the self-defined processes for each incinerator line and predefined processes from Ecoinvent 3.6 database. 
Table 1: Indaver's grate and fluidized bed incinerator line inventory, 2018 annual operation data (Indaver, 2018) 


\begin{tabular}{|c|c|c|c|c|c|}
\hline & & Utility & Unit & $\begin{array}{l}\text { Grate } \\
\text { Incinerator } \\
\text { line }\end{array}$ & $\begin{array}{l}\text { Fluidized Bed } \\
\text { Incinerator line }\end{array}$ \\
\hline \multirow[t]{11}{*}{ Input } & & Non-recyclable waste & tons & 432204 & 640642 \\
\hline & & Of which biogenic & $\%$ & 49 & 56 \\
\hline & \multirow[t]{3}{*}{ Energy } & Electricity & $\mathrm{MWh}$ & 46076 & 71209 \\
\hline & & Steam & GJ & 84261 & 107308 \\
\hline & & Heavy fuel oil & tons & 336 & 688 \\
\hline & \multirow[t]{6}{*}{$\begin{array}{l}\text { Flue gas } \\
\text { cleaning } \\
\text { additives }\end{array}$} & Quicklime & tons & 2088 & 9527 \\
\hline & & Limestone & tons & 2207 & - \\
\hline & & Activated carbon & tons & 268 & - \\
\hline & & Lignite & tons & - & 698 \\
\hline & & Urea (DeNOx) & tons & 1321 & 859 \\
\hline & & $\mathrm{NaOH}$ & tons & - & 202 \\
\hline \multirow[t]{13}{*}{ Output } & Energy & $\begin{array}{l}\text { Recovered in the form of } \\
\text { high-pressure steam }\end{array}$ & GJ & 3660208 & 4297180 \\
\hline & \multirow[t]{10}{*}{$\begin{array}{l}\text { Direct air } \\
\text { emissions }\end{array}$} & $\mathrm{CO}_{2}$ & tons & 469930 & 624290 \\
\hline & & $\mathrm{NO}_{\mathrm{x}}$ & tons & 337 & 262 \\
\hline & & $\mathrm{SO}_{2}$ & $\mathrm{~kg}$ & 3800 & 2000 \\
\hline & & $\mathrm{CO}$ & $\mathrm{kg}$ & 9600 & 34900 \\
\hline & & Particulate matter & $\mathrm{kg}$ & 1500 & 1300 \\
\hline & & $\mathrm{HCl}$ & $\mathrm{kg}$ & 1100 & 500 \\
\hline & & TOC & $\mathrm{kg}$ & 500 & 2600 \\
\hline & & Mercury & $\mathrm{kg}$ & $<11$ & 19 \\
\hline & & Cadmium & $\mathrm{kg}$ & $<11$ & $<14$ \\
\hline & & Thallium & $\mathrm{kg}$ & $<11$ & $<14$ \\
\hline & \multirow[t]{2}{*}{$\begin{array}{l}\text { Residual } \\
\text { products }\end{array}$} & Bottom ash sludge & tons & 18430 & 27285 \\
\hline & & Ferro metals & tons & 8095 & 9600 \\
\hline
\end{tabular}




\begin{tabular}{|llll|}
\hline Aluminium scrap & tons & 2253 & 1440 \\
\hline Copper scrap & tons & 751 & 480 \\
\hline Granulates & tons & 28639 & - \\
\hline Sand & tons & 26484 & - \\
\hline Gypsum & tons & 1378 & - \\
\hline Electrostatic filter and boiler & tons & 6284 & 91752 \\
ash & & & \\
\hline Semi-wet cleaning residue & tons & 7584 & 17086 \\
\hline
\end{tabular}

\subsubsection{Energy Output Scenarios}

Four scenarios (illustrated in Fig. 2) were established by varying the distribution of recovered energy, in the form of high-pressure steam, to the steam turbine for electricity production or to the high-pressure steam network. The operational energetic requirements (electricity and steam inputs) of the incinerator lines are provided by the WtE plant on site.

The first scenario, 'Electricity', represents WtE operation where the only available energetic output is electricity generated by a steam turbine on site and, subsequently, supplied to the Belgian national grid (Fig. 2a). The second and third scenarios, 'Electricity and Steam' and 'Steam', employ the ECLUSE highpressure steam network which connects Indaver/Sleco's WtE plant to neighboring chemical companies in Doel, therefore avoiding conventional steam production for those companies. The 'Electricity and Steam' scenario models the 2018 operation of Indaver/Sleco's WtE plant, where a small portion (580 TJ) of the produced steam was sold to neighboring chemical companies via the ECLUSE network, however the majority of the steam $(7185 \mathrm{TJ})$ was sent to the steam turbine and the available electricity was subsequently sold to the national grid (Fig. 2b). The third scenario, 'Steam' scenario, assumes that only the steam needed to provide the electricity consumed on site, flows to the turbine. All other high-pressure steam produced is delivered to neighboring chemical companies via the ECLUSE steam network (Fig. 2c). The fourth scenario 'Electricity and Steam with CCS', represents WtE operation involving a hypothetical monoethanolamine (MEA) based carbon capture and conditioning unit coupled to the WtE plant with hypothetical $\mathrm{CO}_{2}$ storage facilities in the North Sea (Fig. 2d). Despite its high energy consumption, the MEA post-combustion process was selected as the technology due to its maturity. The operational requirements of the carbon capture and conditioning process as well as the shipping reconditioning characteristics used in this study are shown in Table 2. In the scrubber unit of the carbon capture unit, a $30 \%$ MEA solution absorbs the CO2 at typically 1 bar and $25-50^{\circ} \mathrm{C}$ with an efficiency of $85-95 \%$ (Tang \& You, 2018). The $\mathrm{CO}_{2}$ recovery efficiency was taken as $90 \%$ (Rao \& Rubin, 2002). Further details on the MEA technology for carbon capture can be found in literature (Rao \& Rubin, 2002; Jakobsen et al., 2016). After $\mathrm{CO}_{2}$ conditioning, the obtained liquid $\mathrm{CO}_{2}\left(6.5\right.$ bar and $\left.-50^{\circ} \mathrm{C}\right)$ was assumed to be transported via ship to Dutch North Sea storage facilities. This assumption was based on recent studies that investigate the feasibility of large-scale CCS projects in the Dutch North Sea (Neptune Energy, 2020). The shipping 
distance to the storage facilities was assumed as $470 \mathrm{~km}$, which was an estimation using USGS (2003) as reference. The results of the four scenarios were compared to identify the influence of energy output and substitution on the environmental performance of the WtE plant.

Table 2: Operational requirements for the MEA-based carbon capture and conditioning unit and shipping conditioning and transport chain design characteristics (Jakobsen et al., 2016).

\begin{tabular}{|c|c|c|c|}
\hline & Utilities consumption & Value & Unit \\
\hline \multirow[t]{4}{*}{ Capture } & Low-pressure steam & 3.2 & $\mathrm{GJ} /$ ton $\mathrm{CO}_{2}$ captured \\
\hline & Electricity & 14.2 & $\mathrm{kWh} /$ ton $\mathrm{CO}_{2}$ captured \\
\hline & Cooling water & 30 & $\mathrm{~m}^{3} /$ ton $\mathrm{CO}_{2}$ captured \\
\hline & Amine make-up & 0.8 & $\mathrm{~kg}_{\text {MEA }} /$ ton $\mathrm{CO}_{2}$ captured \\
\hline Conditioning & Electricity & 100.7 & $\mathrm{kWh} /$ ton $\mathrm{CO}_{2}$ captured \\
\hline Shipping & Ship fuel consumption & 5.41 & $\begin{array}{l}\mathrm{g}_{\text {fuel }} / \text { ton } \mathrm{CO}_{2} \text { captured / } \\
\mathrm{km}\end{array}$ \\
\hline \multirow{3}{*}{$\begin{array}{l}\text { On-board } \\
\text { reconditioning }\end{array}$} & On-board pump efficiency & 75 & $\%$ \\
\hline & $\mathrm{CO}_{2}$ pump power & 1200 & $\mathrm{~kW} /$ pump \\
\hline & $\begin{array}{l}\text { Shipping fuel conversion } \\
\text { factor }\end{array}$ & 12.029 & $\mathrm{kWh} /$ ton of fuel \\
\hline
\end{tabular}

In the LCA models, the operational electricity and low-pressure steam requirements for the carbon capture and conditioning process were assumed to be provided onsite by the WtE plant. The low-pressure steam needed in the carbon capture process was assumed to be provided onsite by the low-pressure bleed steam from the steam turbine, corresponding to $80 \%$ of the energy output of this turbine. To meet the relatively high low-pressure steam demand in the form of bleed of the turbine, more electricity is produced than is consumed on site. The over production of electricity ( $85 \mathrm{GWh}$ ) was assumed to be delivered to the national electricity grid.

\subsection{Comparative analysis models}

To conduct a comparative analysis, and thus investigate the influence of the energy substitution processes on the overall environmental impact, two LCA models were made. Both models model the operation of Indaver/Sleco's WtE plant under the same four energy output scenarios as described in Sect. 2.3.1. The difference between Model 1 and Model 2 is that the predefined processes selected from the Ecoinvent 3.6 database to represent the avoided conventional energy production (energy substitution 
processes) are based on national and European average values (in Model 1) and on natural gas (in Model 2).

\subsubsection{Model 1}

The assumed avoided conventional electricity production process in Model 1 was the 'Belgian market for medium voltage electricity' process. All 'markets for electricity' processes in the Ecoinvent 3.6 database use statistical data from 2014 to form the cut-off and APOS model for the national production of electricity, imports and exports of electricity are not considered (Ecoinvent, 2016). The Belgian sources of electricity production in 2014 are equitable to that used in Model 1. Nuclear (49\%) and fossil fuels (oil and petroleum products, natural gas, solid fossil fuels) (31.4\%) mainly comprise the 2014 Belgian market for electricity, whereas renewables and biofuel accounted for 19.5\% (Eurostat, 2021).

It is important to mention that using 'Belgian market for medium voltage electricity' as the avoided conventional production process has its shortcomings; one being the inaccuracy introduced by assuming $1 \mathrm{kWh}$ produced by the $\mathrm{WtE}$ plant would replace $1 \mathrm{kWh}$ from the average national electricity mix, in reality it would replace $1 \mathrm{kWh}$ of a specific electricity supply. According to the merit order, power plants that continuously produce electricity at very low marginal cost are the first to be called upon to supply electricity. Power plants with higher marginal costs are subsequently added until demand is met. Additional factors such as flexibility, fixed costs, as well as investment costs and dismantling costs, influence which supplier will be prioritized within the electricity market (Next Kraftwerke, 2019). In this regard, renewables and nuclear power would be prioritized to supply electricity due to their almost negligible marginal cost and inflexibility, respectively. The most flexible electricity suppliers or those with relatively high marginal cost, e.g., natural gas power plants, would be the suppliers which would be replaced by the WtE plant. This shortcoming illustrates the complexity of the energy system which is modelled in the LCA and emphasizes that the conclusions drawn in LCA's depend on the energy substitution assumptions made during the modelling process.

The avoided process that was assumed for the production of steam in Model 1 was 'Steam production, as an energy carrier, in the chemical industry [RER]'. This Ecoinvent process represents the European average mix for fuels used to produce steam in the chemical industry. The fuels associated with this process were identified as being ca. $62 \%$ natural gas, $18 \%$ crude oil, and $16 \%$ hard coal (see Online Resource 1). Again, it can be argued that this substitution process might not be the most representative, since most of the companies that are connected to the ECLUSE steam network would otherwise produce steam in a natural gas or fuel oil boiler.

\subsubsection{Model 2}

Due to the aforementioned shortcomings of the substituted energy processes in Model 1, Model 2 was modelled so that the avoided conventional electricity and steam production processes selected from the Ecoinvent 3.6 database were 'electricity production, natural gas, conventional power plant [BE]' and 'heat 
production, natural gas, at industrial furnace [Europe without Switzerland]'. Comparison between the two models will therefore quantify the influence of energy substitution in this specific LCA modeling.

\section{Life Cycle Assessment Results And Discussion}

All LCA results are presented using the normalized environmental impact value, therefore, the unit is Average European Citizen Equivalent (AECE).

\subsection{Life Cycle Assessment results: Model 1}

Figure 3a displays the normalized results of six considered ICs. The results from Model 1 show that by maximizing the use of the recovered energy as high pressure steam, Indaver/Sleco's WtE plant can avoid an annual environmental impact of approximately 21200, 36800, 6700, 15800, 37000 and 6900 AECE in the ICs 'climate change', 'freshwater and terrestrial acidification', 'freshwater eutrophication, 'photochemical ozone creation' and 'respiratory effects, inorganics', 'terrestrial eutrophication', respectively.

The results clearly illustrate the significant variation in normalized impact values between the four scenarios in the IC 'climate change'. Causative factors of this variation will be discussed in detail in Sect. 3.1.1. For all three ICs - 'climate change', 'terrestrial eutrophication' and 'photochemical ozone creation' - the 'Steam' and the 'Electricity and Steam with CCS' scenarios result in negative (thus, avoided) or negligible environmental impact, whilst the 'Electricity and Steam' and 'Electricity' scenarios result in a positive environmental impact value. The remaining ICs - 'freshwater and terrestrial acidification', 'freshwater eutrophication' and 'respiratory effects, inorganics' - all four energy output scenarios resulted in negative environmental impact values.

The results of Fig. 3a illustrate a common ranking of the different scenarios in all IC's (except for 'climate change'). From least to most environmental impact this ranking is 'Steam', 'Electricity and Steam with CCS', 'Electricity and Steam', and finally the 'Electricity'. This means that by coupling a MEA-based CCS process, similar to that modelled in this study, to WtE, only environmental impact in the IC 'climate change' will be reduced. In this particular case, the 'Electricity and Steam with CCS' scenario further reduces the environmental impact value by ca. 28300 AECE compared to the 'Steam' scenario in the IC 'climate change'. However, for all other IC's, the 'Steam' scenario has the largest avoided impact. These results corroborate that of Lausselet et al. (2017).

There are two explanations for the relatively poor environmental performance of the scenario with CCS compared to the 'Steam' scenario. Firstly, the electrical requirements for the capture and conditioning of $\mathrm{CO}_{2}$ were assumed to be provided by the steam turbine on site, therefore diverting steam from being sold to neighboring chemical companies and consequently reducing the avoided volume of conventional production of steam. Secondly, auxiliary inputs and outputs related to the CCS process, such as the production of MEA or the transportation of liquid $\mathrm{CO}_{2}$ to the storage facilities in the North Sea, also contribute to the overall environmental impact. These observations illustrate that reducing the 
environmental impact associated with global warming and $\mathrm{CO}_{2}$ emissions (e.g., installing a CCS process), may cause larger environmental impacts in other ICs. However, these results do not imply that CCS should not be investigated or considered as a viable addition to WtE but rather indicates that further research is necessary which investigates other state-of-the-art CCS or CCU techniques coupled with WtE, which aligns with the conclusion drawn by Christensen et al. (2021).

To identify sub-processes that contribute to the overall environmental impact value in one IC shown in Fig. 3a, the individualized results in the ICs 'climate change', 'respiratory effects, inorganics' and 'photochemical ozone creation' in Model 1 (shown in Fig. 4a, Fig. 4b, and Fig. 4c respectively) will be discussed in detail in the Sect. 3.1.1, 3.1.2, 3.1.3. These three ICs were selected for further discussion due to the magnitude of their overall result shown in Fig. 3a as well as having a variety of causative pollutants.

\subsubsection{Climate change}

Figure 4a illustrates the normalized environmental impact values in the IC 'climate change' for the six processes that contribute to over $97 \%$ of the total environmental impact in the IC 'climate change'. The 'Electricity and Steam with CCS' scenario results in an environmental impact value approximately 26600 AECE and 32600 AECE less than the other three scenarios for the grate and fluidized bed incinerator line processes, respectively. The relatively large environmental impact values, ca. 30900 AECE and 38400 $A E C E$, for the grate and fluidized bed incinerator lines respectively, seen in the other three scenarios, can be mainly attributed to the non-biogenic $\mathrm{CO}_{2}$ that is emitted at the stack. The scenario with CCS captures $90 \%$ of the total $\mathrm{CO}_{2}$ before the flue gases are emitted, therefore reducing environmental impact. $\mathrm{CO}_{2}$ is an inherent product during the combustion of MSW in the presence of oxygen, therefore it's environmental impact can only be minimized by decreasing the fossil waste fraction in the input waste composition, or by capturing the $\mathrm{CO}_{2}$ at the stack. However, the addition of CCS has not reduced the environmental impact to zero for the grate and fluidized bed incinerator line processes, i.e., the impact value is ca. 4300 AECE and 5800 AECE respectively. This remaining environmental impact can be attributed to the $10 \%$ of direct $\mathrm{CO}_{2}$ emission that was not captured in the CCS process, as well as the indirect greenhouse gas emissions of auxiliaries required by the CCS process and the incinerator line processes e.g., the greenhouse gas emissions from the production of urea and activated carbon.

The process 'steam production, as an energy carrier, in the chemical industry' results in the largest absolute avoided environmental impact: the 'Steam', 'Electricity and Steam with CCS', 'Electricity and Steam' scenario have a value of ca. $-80800,-49100$, and -7400 AECE respectively.

The scenario with CCS results in a smaller avoided environmental impact than the 'Steam' scenario because a smaller volume of conventional steam production was avoided by the neighboring chemical industry: 6300 TJ in the 'Steam' and 3826 TJ for 'Electricity and Steam with CCS' scenario (see Fig. 2). However, this difference in avoided emission (ca. 31700 AECE) is more than compensated by the combined reduced impact of both incinerator line processes (ca. 59200 AECE). 
In the process 'market for electricity, medium voltage', 'Electricity', 'Electricity and Steam', and 'Electricity and Steam with CCS' scenario have a relatively modest environmental impact values of ca. -14500 , -13200 , and - 2400 AECE respectively. Indeed, nuclear power and renewable sources, which do not directly emit $\mathrm{CO}_{2}$ during electricity production, make up $68.5 \%$ of the 2014 Belgian electricity mix (Eurostat, 2021). This can explain the relatively low avoided environmental impact for the IC 'climate change'. In contrast, the process used for conventional steam production, uses fossil fuels such as natural gas, hard coal and crude oil, which release non-biogenic $\mathrm{CO}_{2}$ into the atmosphere during combustion, resulting in a relatively large avoided environmental impact in the IC 'climate change' as described above.

\subsubsection{Respiratory effects, inorganics}

Figure $4 \mathrm{~b}$ shows the six processes that contribute to over $94 \%$ of the total environmental impact for the IC 'respiratory effects, inorganics' with their corresponding pollutants. There are two dominant pollutants: $\mathrm{PM}_{2.5}$ and $\mathrm{SO}_{2}$, the former contributes with a larger magnitude in all processes. The processes 'reinforcing steel production' and 'market for aluminum, primary, ingot' result in an overall avoided environmental impact value of ca. -5000 AECE and - 4100 AECE respectively in all four energy output scenarios. Combined ( 9100 AECE), the avoided impact from both substituted metal production processes largely compensates for the combined environmental impact resulting from the operation of both incinerator line processes (ca. 2200 AECE) for all four scenarios.

The 'Steam' scenario, in the process for avoided conventional steam production, results in the largest magnitude avoided impact value (ca. $-16200 \mathrm{AECE}$ and $-11800 \mathrm{AECE}$ for $\mathrm{PM}_{2.5}$ and $\mathrm{SO}_{2}$ respectively) followed by 'Electricity and Steam with CCS' with an environmental impact value of ca. -9800 AECE and 7100 AECE for $\mathrm{PM}_{2.5}$ and $\mathrm{SO}_{2}$ respectively. Hard coal containing sulphur constitutes approximately $14 \%$ of the fuel mix used for the Ecoinvent process 'steam production, as an energy carrier, in the chemical industry' used in Model $1 . \mathrm{SO}_{2}$ is released as a pollutant during hard coal combustion and thus appears as a pollutant during conventional steam production in Model 1 .

\subsubsection{Photochemical ozone creation}

Figure 4c illustrates the normalized environmental impact values in the IC 'photochemical ozone creation' for the six processes that constitute for over $95 \%$ of the total environmental impact in the IC 'photochemical ozone creation'. The combined environmental impact value for the two incineration line processes is ca. $16000 \mathrm{AECE}$ and is attributed to the pollutant $\mathrm{NO}_{\mathrm{x}}$ (see Online Resource 2). $\mathrm{NO}_{\mathrm{x}}$ is formed by either the oxidation of nitrogen compounds contained in the waste (fuel $\mathrm{NO}_{x}$ ) or the oxidation of $\mathrm{N}_{2}$ in the combustion gas (thermal $\mathrm{NO}_{\mathrm{x}}$ ). Fuel $\mathrm{NO}_{\mathrm{x}}$ could be reduced by attempting to lower the nitrogen content of the input waste by applying more stringent separating at source regulations or adding waste sorting processes before incineration takes place. The reduction of thermal $\mathrm{NO}_{x}$ is more difficult because if air is being used as the source of oxygen for the combustion process, the formation of thermal $\mathrm{NO}_{\mathrm{x}}$ is unavoidable. For this reason, end-of-pipe technique are installed to reduce the $\mathrm{NO}_{x}$ in the flue gas. In the 
considered Indaver/Sleco WtE plant, selective non catalytic reduction (SNCR) involving injection of urea in the hot flue gases is installed as an end-of-pipe technique to reduce the amount of $\mathrm{NO}_{x}$ emitted at the stack. Therefore, a way to further reduce the thermal $\mathrm{NO}_{\mathrm{x}}$ emitted would be to improve the de- $\mathrm{NO}_{\mathrm{x}}$ end-ofpipe technique, for example by installing selective catalytic reduction (SCR). However before doing so, it would be important to evaluate whether introducing the SCR technique would indirectly increase the environmental impact of other IC's due to auxiliary exchanges attributed to the new technique (Van Caneghem et al., 2016).

In the process 'steam production, as energy carrier, in chemical industry', the normalized environmental impact value for the 'Steam' scenario is ca. $-23700 \mathrm{AECE}, \mathrm{NO}_{\mathrm{x}}$ being the most contributing pollutant for this process. A fuel present in the average fuel mix used for this process is hard coal, which can account for the emission of $\mathrm{SO}_{2}$ as it is the product of the oxidation of sulphur in the coal during the combustion process.

Due to the relatively large environmental impact of the grate and fluidized bed incinerator line processes (ca. 8900 AECE and 7100 AECE respectively), only the scenarios which avoid a large volume of conventional steam production result in overall negative impact values for this IC. For example, the combined avoided impact value for all pollutants in the avoided conventional steam production process is ca. -23700 AECE from the 'Steam' scenario. It thus compensates for the combined environmental impact caused by both incinerator line processes. Whereas the largest avoided environmental impact value caused by the 'market for electricity, medium voltage' process is ca. -4400 AECE and thus cannot compensate for the environmental impact caused by both incinerator line processes.

\subsection{Life Cycle Assessment results: Model 2}

Figure $3 \mathrm{~b}$ displays the normalized LCA results for the same six ICs used for the evaluation of Model 1. The scale on the $y$-axis in Fig. 3a and Fig. $3 b$ is equivalent illustrating the clear difference between the results of Model 2 compared to Model 1. That is, 19 out of 24 LCA results from Model 1 varied by more than $50 \%$ when compared to Model 2. The results of Model 1 show that the 'Steam' scenario has an environmental advantage over the 'Electricity' scenario for all six ICs measured, however contrarily, in Model 2, the 'Steam' scenario results in less avoided environmental impact compared to the 'Electricity' scenario in the ICs 'freshwater and terrestrial acidification', 'photochemical ozone creation' and 'terrestrial eutrophication'. There are two causes of this disparity: firstly, the environmental impact of producing $1 \mathrm{MJ}$ of heat with natural gas is lower in all six ICs compared to the production of $1 \mathrm{MJ}$ of steam using the European average steam production mix (see Online Resource 3). For example, the environmental impact of producing $1 \mathrm{MJ}$ of heat in a natural gas industrial furnace (as in Model 2 ) is $17 \%, 38 \%$ and $34 \%$, relative to European steam production mix (as in Model 1) for the ICs 'freshwater and terrestrial acidification', 'photochemical ozone creation' and 'terrestrial eutrophication', respectively (see Online Resource 3). Secondly, the three mentioned ICs result in an larger avoided environmental impact for the production of $1 \mathrm{kWh}$ using a natural gas fueled power plant compared to the Belgian national electricity mix. For example, in the IC 'freshwater and terrestrial acidification', the production of $1 \mathrm{kWh}$ in a natural gas power 
plant (as in Model 2) has a relative impact that is 1.28 larger than the Belgian electricity mix (as in Model 1), which, indeed, results in a reduced avoided impact in Model 2 compared to Model 1 (see Online Resource 3). Therefore, in Model 2, scenarios that produce steam rather than electricity will result in smaller avoided environmental impacts. Consequently, both the 'Electricity' and 'Electricity and Steam' scenarios show improved overall environmental impact values for four of the six ICs in Model 2 compared to Model 1 (as displayed in Fig. 3). For instance, the normalized impact value, in the IC 'climate change', was ca. 45000 AECE for the 'Electricity' scenario in Model 1 and was reduced to ca. 14200 AECE in Model 2 and in the IC 'photochemical ozone creation' the normalized impact value was ca. 3200 AECE in Model 1 and was reduced to ca. -8300 AECE.

These results illustrate how the LCA practitioner's selection of predetermined substitution processes, available on the Ecoinvent or other databases, has a significant effect on the overall results of the LCA. They show the importance of using processes that best model reality, thus reducing as much uncertainty as possible. Furthermore, the results and discussion above make it clear, in a quantitative way, that there is no general rule for the determination of the environmental performance of WtE plants since it depends largely on the (assumed) avoided energy production processes. This corroborates with conclusions drawn by Boesch et al. (2014).

\section{Conclusion}

Recovery of energy from MSW during WtE operation upholds the core principles of the circular economy, in that it replaces primary resources by further utilizing non-recyclable waste which otherwise would be disposed. This study considers a state-of-the-art WtE plant located in Belgium, consisting of three grate incinerators and three fluidized bed incinerators, situated in industrial symbiosis, i.e. being connected to both a steam turbine onsite and the surrounding chemical industry via a high-pressure steam network. To investigate how the recovered energy can be utilized best to mitigate environmental impact, an LCA comprising four different scenarios was conducted.

The scenario in which all the produced high pressure steam is fed in the existing steam network and used as heat source by the surrounding chemical companies had the largest normalized avoided environmental impacts, followed by the scenario in which CCS is added to this setting (except for the IC 'climate change' in which the CCS scenario obviously resulted in the largest avoided impact). Specifically, by utilizing the recovered energy solely as industrial heat source, the considered WtE plant can avoid an annual environmental impact of approximately 21200, 36800, 6700, 15800, 37000 and 6900 AECE in the ICs 'climate change', 'freshwater and terrestrial acidification', 'freshwater eutrophication, 'photochemical ozone creation' and 'respiratory effects, inorganics', 'terrestrial eutrophication', respectively. Implementing a MEA-based CCS unit indeed reduced greenhouse gas emissions, therefore reducing the environmental impact for the grate and fluidized bed incinerator line processes by ca. 26600 AECE and 32600 AECE, respectively, compared to the other three scenarios in the IC 'climate change'. However, due to the operational electrical and low-pressure steam requirements of the $\mathrm{CO}_{2}$ conditioning, the MEA-recovery step as well as other auxiliary processes affiliated to the CCS, the CCS scenario results in less avoided 
environmental impact in the other five ICs compared to the steam scenario without CCS. This illustrates that reducing the environmental impact associated with climate change may cause larger environmental impacts in other ICs.

Furthermore, a comparative analysis showed the effect of the assumed avoided energy production processes on the overall environmental impact of the WtE plant: the first model assumed avoided conventional production processes for electricity and steam production based on national and European averages respectively, whereas in the second model, both steam and electricity avoided conventional production processes were based on natural gas. In the second Model, scenarios that produce steam resulted in smaller avoided environmental impacts, whereas the scenarios that mainly produce electricity resulted in a larger avoided environmental impact. This comparative analysis proved that not only the energy outputs, but also the assumed avoided energy production processes have a significant effect on the overall results of the LCA.

Conclusively, this study shows that the utilization of recovered energy from the considered WtE plant can be optimized to mitigate environmental impacts by exploiting their position within industrial symbiosis and supplying high-pressure steam to neighboring chemical industry via the existing steam network. By doing so, the WtE plant achieves negative normalized environmental impact values in all six ICs analyzed in this study, thus avoiding emissions. Therefore, it demonstrates the environmental benefit WtE realizes, by substituting conventional energy production processes that are reliant on primary resources, whilst performing its primary function that is reducing the volume and mass of non-recyclable waste, destroying hazardous organic components present in domestic and industrial non-hazardous waste, and recovering useful materials from it. Applying the energy recovered directly as a heat source, in this way avoiding heat production from fossil fuels, instead of producing electricity will become more and more interesting from an environmental point of view, given the expected increasing share of renewable electricity in the electricity mix.

\section{Abbreviations}

AECE Average European Citizen Equivalent

APC Air pollution control

CCS Carbon capture and storage

IC Impact category

IS Industrial symbiosis

LCA Life cycle assessment

MEA Monoethanolamine 
MSW Municipal solid waste

RL Recommendation level

SCR Selective catalytic reduction

SNCR Selective non catalytic reduction

WtE Waste to energy

\section{Declarations}

Funding

Not applicable.

\section{Conflicts of interest/Competing interests}

Not applicable.

\section{Availability of data and material}

All data used for this research is publicly available. References are given throughout the article. Additional data from LCA results are available on reasonable request.

\section{Code availability}

Available on reasonable request.

\section{Ethics approval}

Not applicable.

\section{Consent to participate}

Not applicable.

\section{Consent for publication}

All authors give their full consent for publication. 


\section{References}

1. Astrup, T. F., Tonini, D., Turconi, R., \& Boldrin, A. (2015). Life cycle assessment of thermal Waste-toEnergy technologies: Review and recommendations. Waste Management, 37, 104-115. https://doi.org/10.1016/j.wasman.2014.06.011

2. Boesch, M. E., Vadenbo, C., Saner, D., Huter, C., \& Hellweg, S. (2014). An LCA model for waste incineration enhanced with new technologies for metal recovery and application to the case of Switzerland. Waste Management, 34(2), 378-389. https://doi.org/10.1016/j.wasman.2013.10.019

3. Brunner, P. H., \& Rechberger, H. (2015). Waste to energy - key element for sustainable waste management. Waste Management, 37, 3-12. https://doi.org/10.1016/j.wasman.2014.02.003

4. Burnley, S., Coleman, T., \& Peirce, A. (2015). Factors influencing the life cycle burdens of the recovery of energy from residual municipal waste. Waste Management, 39, 295304. https://doi.org/10.1016/j.wasman.2015.02.022

5. Christensen, T. H., \& Bisinella, V. (2021). Climate change impacts of introducing carbon capture and utilisation (CCU) in waste incineration. Waste Management, 126, 754-

770. https://doi.org/10.1016/j.wasman.2021.03.046

6. Dastjerdi, B., Strezov, V., Rajaeifar, M. A., Kumar, R., \& Behnia, M. (2021). A systematic review on life cycle assessment of different waste to energy valorization technologies. Journal of Cleaner Production, 290. https://doi.org/10.1016/j.jclepro.2020.125747

7. De Greef, J., Verbinnen, B., \& Van Caneghem, J. (2018). Waste-to-energy: Coupling Waste Treatment to Highly Efficient CHP. International Journal of Chemical Reactor Engineering, 16(10), 112. https://doi.org/10.1515/ijcre-2017-0248

8. Demetrious, A., Verghese, K., Stasinopoulos, P., \& Crossin, E. (2018). Comparison of alternative methods for managing the residual of material recovery facilities using life cycle assessment. In Resources, Conservation and Recycling (Vol. 136, pp. 33-45). Elsevier

B.V. https://doi.org/10.1016/j.resconrec.2018.03.024

9. Ecoinvent. (2016). Electricity Mix Model. https://www.ecoinvent.org/support/faqs/methodology-ofecoinvent-3/how-are-electricity-market-mixes-modelled.html (accessed October 2020).

10. European Commission. (2015). Closing the loop - An EU action plan for the Circular Economy.

11. European Commission. (2018). Supporting information to the characterisation factors of recommended EF Life Cycle Impact Assessment method New models and differences with ILCD. https://doi.org/10.2760/671368

12. European Commission. (2019). The European Green Deal. In European Commission. https://doi.org/10.1017/СВ09781107415324.004

13. European Commission. (2020). A new Circular Economy Action Plan For a cleaner and more competitive Europe.

14. Eurostat. (2021). Production of electricity and derived heat by type of fuel [Data set]. Received from https://appsso.eurostat.ec.europa.eu/nui/submitViewTableAction.do 
15. Grosso, M. (2016). Sound and advanced municipal waste management: Moving from slogans and politics to practice and technique. Waste Management \& Research. 34, 977-979. https:/doi.org/10.1177/0734242X16671100

16. Haupt, M., Kägi, T., Hellweg, S. (2018). Modular life cycle assessment of municipal solid waste management. Waste Management. 79, 815-827. https://doi.org/10.1016/j.wasman.2018.03.035.

17. Indaver. (2018). Your partner in the circular economy - Indaver's Sustainability Report. https://www.indaver.de/fileadmin/indaver.de/pdf/sustainability-report/indaver-sustainabilityreport-2018-key-figures-en.pdf (accessed October 2020).

18. Jakobsen, J., Roussanaly, S., \& Anantharaman, R. (2016). A techno-economic case study of CO 2 capture, transport and storage chain from a cement plant in Norway. https://doi.org/10.1016/j.jclepro.2016.12.120

19. Jeswani, H. K., \& Azapagic, A. (2016). Assessing the environmental sustainability of energy recovery from municipal solid waste in the UK. Waste Management, 50, 346363. https://doi.org/10.1016/j.wasman.2016.02.010

20. Kral, U., Morf, L. S., Vyzinkarova, D., \& Brunner, P. H. (2019). Cycles and sinks: two key elements of a circular economy. Journal of Material Cycles and Waste Management, 21(1), 19. https://doi.org/10.1007/s10163-018-0786-6

21. Lausselet, C., Cherubini, F., Oreggioni, G. D., del Alamo Serrano, G., Becidan, M., Hu, X., Rørstad, P. K., \& Strømman, A. H. (2017). Norwegian Waste-to-Energy: Climate change, circular economy and carbon capture and storage. Resources, Conservation and Recycling, 126, 5061. https://doi.org/10.1016/j.resconrec.2017.07.025

22. Margallo, M., Aldaco, R., Bala, A., Fullana, P., \& Irabien, A. (2018). Contribution to closing the loop on waste materials: valorization of bottom ash from waste-to-energy plants under a life cycle approach. Journal of Material Cycles and Waste Management, 20(3), 15071515. https://doi.org/10.1007/s10163-018-0709-6

23. Neptune energy Announces feasibility study into CCS plan for Netherlands. (2020, October 12). Retrieved May 13, 2021, from https://www.neptuneenergy.com/media/pressreleases/year/2020/neptune-energy-announces-feasibility-study-ccs-plan-netherlands

24. Next Kraftwerke. (2019). Merit Order: How Ancillary Services Get Their Price. https://www.nextkraftwerke.com/knowledge/what-does-merit-order-mean (accessed October 2020).

25. Quicker, P., Consonni, S., Grosso, M. (2020) The Zero Waste utopia and the role of waste-to-energy. Waste Management and Research, 38, 481-484

26. Rao, A. B., \& Rubin, E. S. (2002). A technical, economic, and environmental assessment of aminebased $\mathrm{CO} 2$ capture technology for power plant greenhouse gas control. Environmental Science and Technology, 36(20), 4467-4475. https://doi.org/10.1021/es0158861

27. Schneider, D. R., \& Ragossnig, A. M. (2015). Recycling and incineration, contradiction or coexistence? Waste Management and Research, 33(8), 693-695. https://doi.org/10.1177/0734242X15593421 
28. Tang, Y., \& You, F. (2018). Multicriteria Environmental and Economic Analysis of Municipal Solid Waste Incineration Power Plant with Carbon Capture and Separation from the Life-Cycle Perspective. ACS Sustainable Chemistry and Engineering, 6(1), 937956. https://doi.org/10.1021/acssuschemeng.7b03283

29. Thyberg, K. L., \& Tonjes, D. J. (2017). The environmental impacts of alternative food waste treatment technologies in the U.S. Journal of Cleaner Production, 158, 101108. https://doi.org/10.1016/j.jclepro.2017.04.169

30. USGS. (2003). Carboniferous-Rotliegend Total Petroleum System Description and Assessment Results Summary. https://pubs.usgs.gov/bul/b2211/b2211.html (accessed October 2020).

31. Van Caneghem, J., Block, C., Van Brecht, A., Van Royen, P., Jaspers, M., Wauters, G., Vandecasteele, C. (2010). Mass balance for POPs in a real scale fluidised bed combustor co-incinerating automotive shredder residue. Journal of Hazardous Materials. 181, 827-

835. https://doi.org/10.1016/j.jhazmat.2010.05.088 https://doi.org/10.1016/j.jhazmat.2010.05.088.

32. Van Caneghem, J., De Greef, J., Block, C., \& Vandecasteele, C. (2016). NOx reduction in waste incinerators by selective catalytic reduction ( SCR) instead of selective non catalytic reduction ( SNCR ) compared from a life cycle perspective: a case study. Journal of Cleaner Production, 112(x), 4452-4460. https://doi.org/10.1016/j.jclepro.2015.08.068

33. Van Caneghem, J., Van Acker, K., De Greef, J., Wauters, G., \& Vandecasteele, C. (2019). Waste-toenergy is compatible and complementary with recycling in the circular economy. In Clean Technologies and Environmental Policy. Springer Verlag. https://doi.org/10.1007/s10098-01901686-0

34. Vandecasteele, C., Wauters, G., Arickx, S., Jaspers, M., Van Gerven, T. (2007). Integrated municipal solid waste treatment using a grate furnace incinerator: The Indaver case. Waste Management. 27, 1366-1375. https://doi.org/10.1016/j.wasman.2006.08.005.

35. Zhou, Z., Tang, Y., Dong, J., Chi, Y., Ni, M., Li, N., \& Zhang, Y. (2018). Environmental performance evolution of municipal solid waste management by life cycle assessment in Hangzhou, China. Journal of Environmental Management, 227, 23-33. https://doi.org/10.1016/j.jenvman.2018.08.083

\section{Figures}




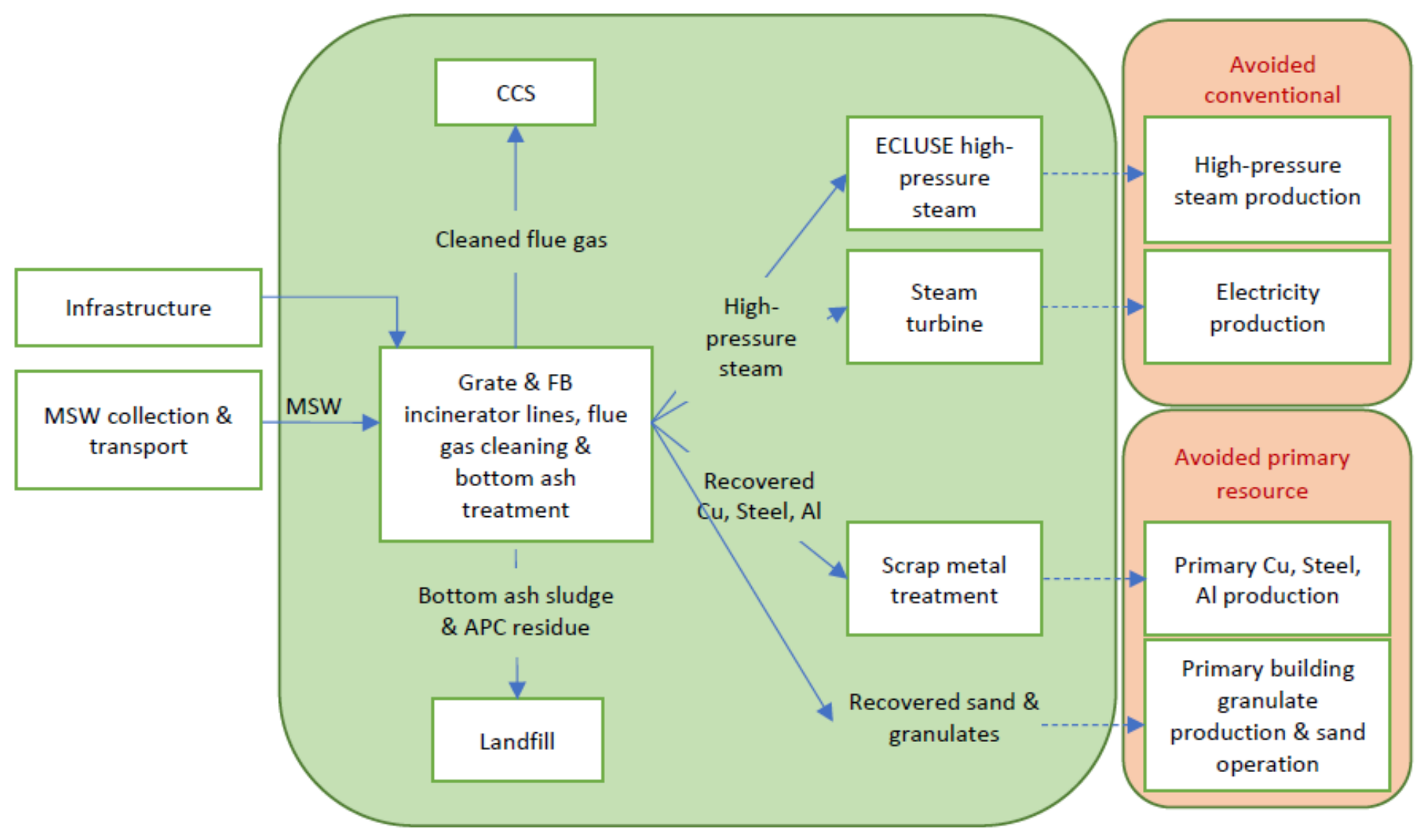

Figure 1

System boundaries diagram of WtE technology at Indaver's site in Doel 


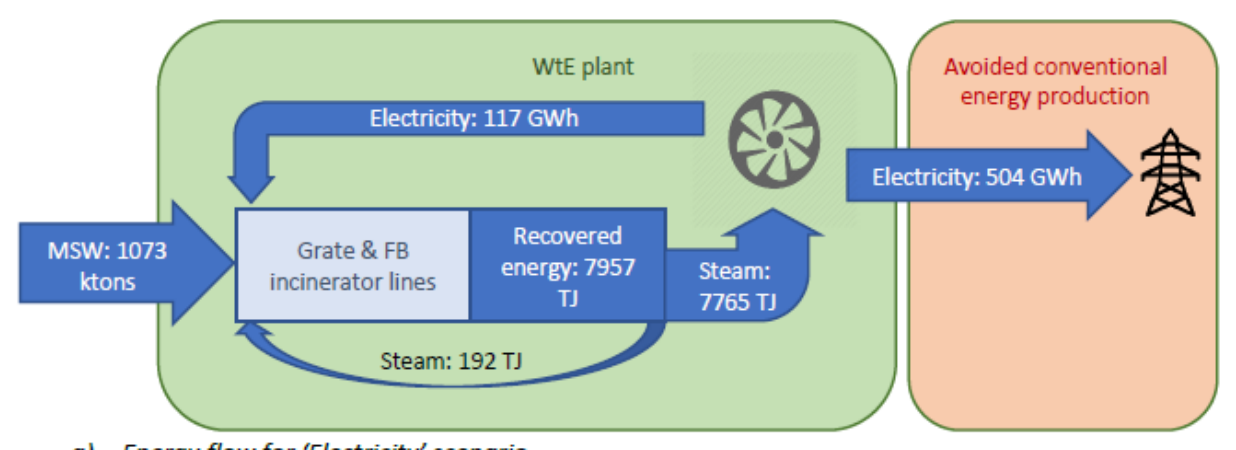

a) Energy flow for 'Electricity' scenario

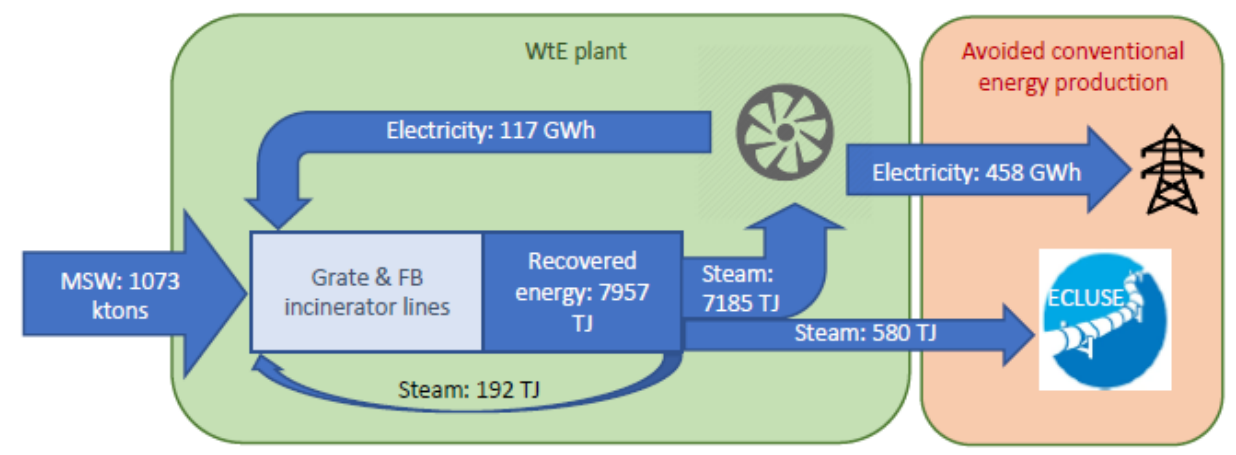

b) Energy flow for 'Electricity and Steam' scenario

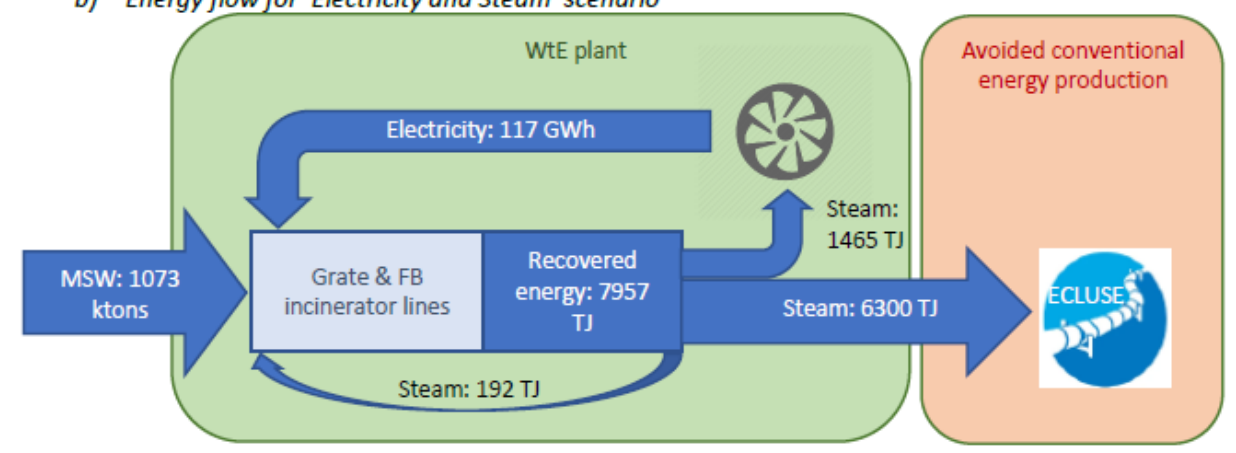

c) Energy flow for 'Steam' scenario

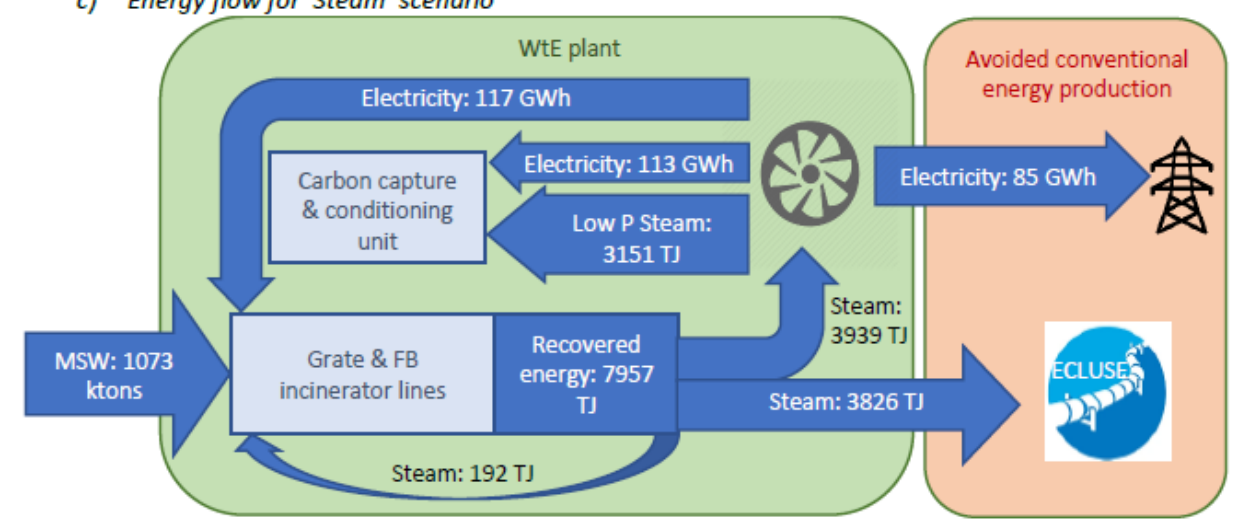

d) Energy flow for 'Electricity and Steam with CCS' scenario

\section{Figure 2}

Energy flows for the four energy output scenarios a)'Electricity', b) 'Electricity and Steam', c) 'Steam', d) 'Electricity and Steam with CCS' 

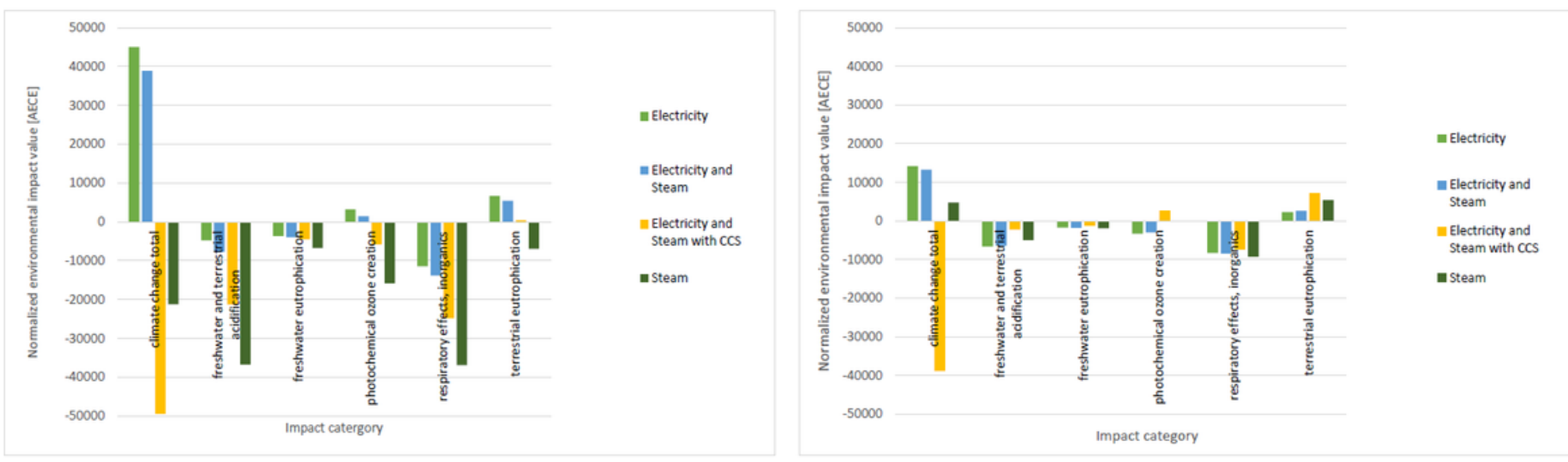

a) Model 1

b) Model 2

\section{Figure 3}

Annual normalized environmental impact values of the considered WtE plant (Average European Citizen Equivalent (AECE)) for six EF 2.0 impact categories and which have recommendation level 1 or 2 for a) Model 1 and $b$ ) Model 2
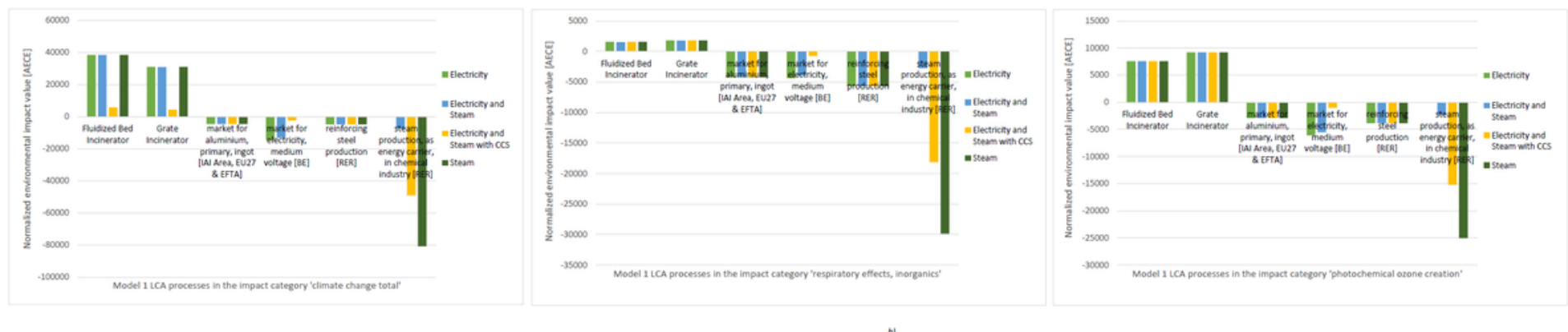

\section{Figure 4}

Annual normalized environmental impact values of the considered WtE plant (Average European Citizen Equivalent (AECE)) for the impact categories a) climate change, and b) respiratory effects, and c) photochemical ozone creation, separated by process

\section{Supplementary Files}

This is a list of supplementary files associated with this preprint. Click to download.

- GraphicalAbstract.docx

- ESM123.docx 